Published in final edited form as:

Psychiatry Res. 2011 August 15; 188(3): 372-376. doi:10.1016/j.psychres.2011.05.006.

\title{
Suicidal ideation in Huntington disease: The role of comorbidity
}

\author{
Heather H. Wetzel ${ }^{a}$, Carissa R. Gehl ${ }^{b}$, Lisa Dellefave ${ }^{c}$, Judith F. Schiffman ${ }^{d}$, Kathleen M. \\ Shannon ${ }^{e}$, Jane S. Paulsen ${ }^{f,}$, , and Huntington Study Group \\ aDivision of Hematology/Oncology, Northwestern University, Chicago, Illinois, United States \\ ${ }^{b}$ Department of Psychiatry and Psychology, Mayo Clinic, Rochester, Minnesota, United States \\ 'Department of Medicine, Section of Cardiology, University of Chicago, Chicago, Illinois, United \\ States \\ dDepartment of Psychiatry and Behavioral Sciences, Northwestern University, Chicago, Illinois, \\ United States \\ eDepartment of Neurological Sciences, Rush University Medical Center, Chicago, Illinois, United \\ States
}

\footnotetext{
*Correspondence and reprint requests to: Jane S. Paulsen, PhD, University of Iowa, Psychiatry Research, 1-305 Medical Education Building, Iowa City, Iowa 52242-1000, jane-paulsen@uiowa.edu, Phone: 319-353-4551, Fax: 319-353-4438 .

Huntington Study Group

Huntington Study Group participating investigators and coordinators: Phillipa Hedges, Elizabeth McCusker, MD, Samantha Pearce, and Ronald Trent, PhD, Westmead Hospital, Sydney, NSW Australia; David Abwender, PhD, Peter Como, PhD, Irenita Gardiner, RN, Charlyne Hickey, RN, Elise Kayson, RN, Karl Kieburtz, MD, Frederick Marshall, MD, Nancy Pearson, RN, Ira Shoulson, MD, and Carol Zimmerman, RN, University of Rochester, NY; Elan Louis, MD, Karen Marder, MD, Carol Moskowitz, RN, Carmen Polanco, BA, Stuart Taylor, MD, and Naomi Zubin, BA, Columbia Presbyterian Medical Center, New York, NY; Catherine Brown, RN, Jill Burkeholder, Mark Guttman, MD, Sandra Russell, Dwight Stewart, MD, and Jackie Thomson, RN, Markham Health Center, Toronto, ONT; Daniel S. Sax, MD, and Marie Saint-Hilaire, MD, Boston University, Boston, MA; Jackie Gray, Cindy Hunter, MS, Nanette Mercado, PhD, Eric Siemers, MD, and Joanne Wojcieszek, MD, Indiana University School of Medicine, Indianapolis, IN; Ted Dawson, MD, Elizabeth Leritz, BS, Adam Rosenblatt, MD, Meeia Sherr, RN, and Candace Young, RN, Johns Hopkins University, Baltimore, MD; Tetsuo Ashizawa, MD, Jenny Beach, RN, and Joseph Jankovic, MD, Baylor College of Medicine, Houston, TX; Jeana Jaglin, RN, and Kathleen Shannon, MD, Rush Presbyterian/St. Luke's Medical Center, Chicago, IL; Anders Lundin, MD, Karolinska Hospital, Stockholm, Sweden; Kathleen Francis, MD, and Kim Lane, UMDNJ Robert Wood Johnson Medical School, Camden, NJ; Alexander Auchus, MD, J. Timothy Greenamyre, MD, Steven Hersch, MD, Randi Jones, PhD, and David Olson, MD, Emory University, Atlanta, GA; Jang-Ho John Cha, MD, Merit Cudkowicz, MD, Walter Koroshetz, MD, Greg Rudolf, Paula Sexton, MA, and Anne B. Young, MD, Massachusetts General Hospital, Boston, MA; Roger Albin, MD, and Kristine Wernette, RN, University of Michigan, Ann Arbor, MI; Donald S. Higgins, MD, and Carson Reider, MS, Ohio State University, Columbus, OH; Vicki Hunt, RN, and Francis Walker, MD, Bowman Gray School of Medicine, Winston-Salem, NC; Robert Hauser, MD, Juan Sanchez-Ramos, MD, and Audrey Walker, RN, University of South Florida, Tampa, FL; Martha Nance, MD, Minneapolis Veterans Administration Medical Center, Minneapolis, MN; Susan Cleary, RN, Gina Rohs, and Oksana Suchowersky, MD, University of Calgary Medical Center, Calgary AB; Kerry Duncan and Lauren Seeberger, MD, Colorado Neurologic Institute, Englewood, CO; Jody Corey-Bloom, MD, Michael Swenson, MD, and Neal Swerdlow, MD, University of California, San Diego, CA; Henry Paulson, MD, PhD, Robert Rodnitzky, MD, Lynn Vining, RN, and Jane Paulsen, PhD, University of Iowa, Iowa City, IA; Wayne Martin, MD, and Marguerite Wieler, BSC, PT, University of Alberta, Edmonton, AB; Alicia Facca, MD, Gustavo Rey, PhD, and William Weiner, MD, University of Miami, FL; Charles Adler, MD, John Caviness, MD, Cindy Lied, RN, and Stephanie Newman, RN Mayo Clinic, Scottsdale, AZ; Andrew Feigin, MD, and Barbara Shannon and Jean Ayan, North Shore University Hospital, Manhasset, NY; Karen Caplan, MSW, Janet Cellar, RN, and Kenneth Marek, MD, Yale University School of Medicine, New Haven, CT; Michael Hayden, MD, Lynn Raymond, MD, and Gina Rohs, University of British Columbia, Vancouver, BC; Leon S. Dure, MD, and Jane Lane, RN, Children's Hospital of Alabama, Birmingham, AL; Diane Brown, RN, Stewart Factor, DO, and Eric Molho, MD, Albany Medical College, Albany, NY; Madeline Harrison, MD, Carol Manning, PhD, and Elke Rost-Ruffner, RN, University of Virginia, Charlottesville, VA; Jonelle Adams, Ruth Cummings, RN, and Vicki Wheelock, MD, University of California Davis, CA; Richard Dubinsky, MD, and Carolyn Gray, RN, University of Kansas Medical Center, Kansas City, KS; Ann Catherine Bachoud-Levi, MD, Hopital Henri Mondor, Creteil, France; Hartmut Meierkord, MD, Universitatsklinikum Charite, Berlin, Germany; Joseph Friedman, MD, and Margaret Lannon, RN, Memorial Hospital of Rhode Island, Pawtucket, RI; Joan Lawrence, MD, Royal Brisbane Hospital, Brisbane, Queensland, Australia; and Allen Rubin, MD, and Rose Schwarz, RN, Allegheny University, Philadelphia, PA. Biostatistics and Coordination Center Staff: Alicia Brocht, BA, Kathy Claude, MS, Joshua Goldstein, and David Oakes, PhD, University of Rochester, Rochester, NY.
} 
fDepartments of Psychiatry and Neurology, University of lowa College of Medicine, lowa City, lowa, United States

\section{Abstract}

Huntington disease (HD) is a neurodegenerative condition characterized by cognitive impairments, motor abnormalities, and psychiatric disturbance. An increased risk for suicide has been documented. The majority of HD research has focused on cognitive and motor features of $\mathrm{HD}$; the implications of psychiatric manifestations have received less consideration. Recent studies have sought to identify the stages of HD in which patients are at increased risk to experience suicidal ideation, though no study has examined possible risk factors for suicidality. The current study examines the presence of psychiatric comorbidity and its involvement in suicidal ideation. Suicidal ideation was examined in 1,941 HD patients enrolled in the Huntington Study Group. Of those, 19\% (N = 369) reported suicidal ideation. Logistic regression analyses indicated that depression/anxiety and aggression/irritability are significant predictors of suicidal ideation $(p<0.01)$. In a subsample with the greatest suicidal ideation, alcohol and drug abuse were also predictive. Findings suggest that suicide in HD may be more distinct as compared to suicide in the general population. It is recommended that all individuals with HD (specifically those with features of depression, aggression, substance abuse) have routine suicide assessment; further research is needed to understand the high rate of suicide in HD.

\section{Keywords}

neurodegenerative; genetic; suicide; psychiatry

\section{Introduction}

Huntington disease (HD) is an autosomal-dominant neurodegenerative disease characterized by cognitive disturbance, motor abnormalities, and psychiatric symptoms. The prevalence of HD is approximately 7-10 per 100,000 individuals (Harper, 1992). HD is caused by an unstable CAG repeat expansion on chromosome 4p; symptoms occur when the expansion is greater than 36 repeats (Harper, 1992). Huntingtin is a cytoplasmic protein expressed at high levels in the striatal neurons vulnerable to degeneration in HD and at low or even undetectable levels in the neurons resistant to degeneration (Ferrante et al., 1997). The striatum, which is composed of the putamen and caudate, is the primary structure of the basal ganglia that is affected by HD, although all areas of the brain have shown deterioration.

While the majority of HD research has centered on motor and cognitive aspects of the disorder, many studies have established that psychiatric features, such as personality changes, affective disorder, or psychosis are also a significant component of HD (Beglinger et al., 2008; Craufurd et al., 2001; Cummings, 1995; Duff et al., 2007; Paulsen et al., 2001; Paulsen and Robinson, 2001; van Duijn et al., 2008). Psychiatric manifestations occur in $35 \%$ to $73 \%$ of patients with HD (see Cummings, 1995) for a review); extreme differences are attributed to study design and assessment approaches. Some reports suggest that psychiatric disturbances in HD are most associated with disability (Dewhurst et al., 1970; Marder et al., 2000; Mayeux et al., 1986), and there is evidence that psychiatric manifestations may predate motor signs by a decade (i.e., Berrios et al., 2001, Campodonico et al., 1996, Folstein et al., 1983).

Suicide is one of the few potentially preventable causes of premature death in this disorder. As such, improved understanding of risk factors for suicide in HD is worthy of renewed 
attention. Completed suicide in HD has been reported to be as high as 13\% (Cummings, 1995), a seven to twelve fold increase above that of the general population's suicide rate of $<1 \%$ (Farrer, 1986; Kessler et al., 2005). Among neurodegenerative disease, suicide rates in Huntington disease remain the highest (Druss and Pincus, 2000; Harris and Barraclough, 1997). Farrer (Farrer, 1986) reported completed suicide rates in HD were $5.7 \%$ while $27.6 \%$ of individuals with HD acknowledged at least one suicide attempt.

In community samples, approximately $90 \%$ individuals who complete suicide have a diagnosable psychiatric disorder at the time of death, substance-use and affective disorders being the most frequent (Bertolote et al., 2003; Cheng, 1995; Chioqueta and Stiles, 2003; Conwell et al., 1996; Kessler et al., 1999; Preuss et al., 2002; Spalletta et al., 1996; Yen et al., 2003). Other known risk factors for completed suicide include current substance abuse, past suicide attempts, incarceration or arrest, access to suicidal means, family history of suicide and current suicidal ideation (Druss and Pincus, 2000; Sher, 2006). Brezo et al. (2006) recently suggested that personality features, such as hopelessness, neuroticism, psychoticism, perfectionism, aggression, and irritability are associated with suicidality. Further research is needed to clarify risk factors for suicidal ideation in HD and the unique role psychiatric disorders may have in the development of suicidality in this disease.

The majority of research completed to date regarding suicide risk in HD has focused on its relationship to genetic testing and the provision of presymptomatic test results (Almqvist et al., 2003; Farrer, 1986; Robins Wahlin et al., 2000) with less emphasis on suicidal ideation and risk over the course of the disease. In order to assess which HD patients are at increased risk to commit suicide, it is first important to identify the specific population that may be at highest risk to target counseling and additional precautions. Paulsen et al. (2005) sought to identify which stages of HD were associated with increased rates of suicidal ideation. They found that the most critical periods of risk are immediately before receiving a diagnosis of Huntington disease and in Stage 2 of the disease, a time when initial, significant disability (i.e., loss of employment) occurs.

To date there have been no identified studies that assess the relation between psychiatric comorbidities and suicidal ideation in HD. It is likely that the diagnosis of HD is associated with increased risk for suicidal ideation; however, it is unclear how psychiatric symptoms, such as depression or substance abuse, may further contribute to increased risk for suicidal ideation. Bertolote et al. (2003) suggest that a feasible suicide prevention strategy should involve the assessment and treatment of psychiatric comorbidities. The current study explores the relation between suicide ideation in patients with Huntington disease and comorbid psychiatric symptoms. Identification of additional factors that are associated with increased suicidal ideation may lead to possible areas of intervention to reduce completed suicide in HD.

\section{Methods}

\subsection{Procedure}

Research participants were recruited as part of an ongoing multi-site study at 43 Huntington Study Group (HSG) sites across North America, Australia, and Europe. Participants completed the Unified Huntington Disease Rating Scale (UHDRS), a standardized measure administered by trained professionals (Huntington Study Group, 1996). Current diagnosis of HD was based upon findings obtained from the motor section of the UHDRS. Possible diagnostic categories were $0=$ normal examination, $1=$ nonspecific motor abnormalities (soft signs), 2 = abnormalities suggesting probable $\mathrm{HD}, 3$ = indisputable motor abnormalities that indicate definite HD. 
Data collected from each of the individual 43 study sites was combined at the University of Rochester Clinical Trials Coordination Center, and data cleaning including creation of an entirely anonymous database occurred at The University of Iowa. Data analyses for the current research project were completed at The University of Iowa. Subjects (or parents/ guardians) gave their informed, voluntary, written consent after the procedures and possible side-effects were fully explained. Institutional Review Board (IRB) approval was obtained from Northwestern University and The University of Iowa.

\subsection{Measure}

The Unified Huntington Disease Rating Scale (UHDRS; Huntington Study Group, 1996) is a standardized clinical rating scale that assesses four components of HD: motor, cognitive, psychiatric, and functional. The psychiatric portion of the UHDRS was primarily used in the current study. This section assesses the frequency and severity of 14 psychiatric symptoms associated with HD, using a semi-structured interview. The following symptoms were considered: sad mood, anxiety, suicidal thoughts, compulsive behavior, irritable behavior, apathy, delusions, and hallucinations. For each symptom, a total score is obtained by multiplying the severity score (rated from $0-4$ ) by the frequency score (rated from 0-4), which results in a minimum score of 0 , maximum of 16 for each symptom. Marder and colleagues (2000) completed a factor analysis of the UHDRS. This factor analysis yielded five psychiatric factors: depression/anxiety, suicidal thoughts, aggressivity, obsessive/ compulsive behavior, and delusions. Hallucinations were grouped into four distinct factors (audiovisual, tactile, gustatory, and olfactory). Only the audiovisual factor was used in the current analyses as the remaining factors occurred in less than $2 \%$ of participants.

Suicidal ideation was measured on the psychiatric portion of the UHDRS and was scored in terms of frequency and severity. Frequency scores were: $0=$ almost never, $1=$ seldom, $2=$ sometimes, $3=$ frequently, $4=$ almost always. Severity scores were measured similarly: $0=$ absent, $1=$ slight, $2=$ mild, $3=$ moderate, $4=$ severe. A total suicidal ideation score was obtained by multiplying frequency by severity with ranges from $0-16$. In addition to the psychiatric symptoms as measured by the UHDRS, the total motor score and the total cognitive score as well as present and past reports of alcohol, drug, and tobacco abuse were analyzed.

\subsection{Participants}

The Huntington Study Group (HSG) collected data on over 4,000 patients with or at risk for HD worldwide; $18 \%$ of those reported suicidal ideation (Paulsen et al., 2005). Because the purpose of this study was to assess suicidal ideation in those with HD, only individuals with a current HD diagnosis score of 2 (probable HD) or 3 (definite HD) on the UHDRS were included in the current study. A total of 3,391 individuals in the database met these criteria. Of the 3,391 individuals with probable or definite Huntington disease, complete data was available for 1,941 individuals.

\subsection{Statistical analysis}

Suicidal ideation was assessed as a categorical variable due to the skewed nature of the distribution. Suicidal ideation was scored as "present" or "absent" based on the suicide severity and frequency item of the UHDRS. Any endorsement of suicidal ideation (i.e., any scores greater than or equal to 1) was scored as "present." This assessment of suicidal ideation serves as the dependent measure in further analyses. Bivariate logistic regression analysis was used to assess whether demographic (age, sex, years of education), motor symptoms, cognitive impairment (Symbol Digit Modalities Test), and/or psychiatric symptoms (UHDRS Depression/Anxiety, Aggression, Obsession/Compulsion factors as well as alcohol, illicit drug, and tobacco use history) would predict the presence or absence of 
suicidal ideation. A $p$-value of 0.01 was considered to be statistically significant. All statistical analyses were performed using SPSS for Windows.

\section{Results}

\subsection{Participant Characteristics}

Demographic characteristics are presented in Table 1. A total of 1,941 participants met criteria for the current study. Participants were primarily Caucasian (95.4\%) and were an average of 47.29 years old. On average, participants had slightly more than a high school education with an average duration of Huntington disease of 6.6 years $(\mathrm{SD}=5.0)$. Participants reported a significant history of seeking treatment for psychiatric disorders including depression (48.2\%), obsessive-compulsive disorder (8.1\%), and psychosis (5.2\%). Nearly one-half of participants (40.3 percent) were currently prescribed anti-depressant medication. A notable minority of participants reported a previous or current history of alcohol or illicit drug abuse.

With regard to suicidality, greater than one-fourth of participants (26.5\%) acknowledged a history of suicidal ideation, while 9.5 percent reported a history of at least one suicide attempt. Nineteen percent of participants $(n=369)$ endorsed current suicidal ideation.

\subsection{Prediction of Suicidal Ideation}

Bivariate logistic regression was used with presence or absence of suicidal ideation as the dependent variable. The overall model was significant $(X=377.12, \mathrm{df}=11, p<0.01)$. None of the demographic, motor, or cognitive variables were significant predictors of presence or absence of suicidal ideation. However, higher UHDRS depression/anxiety $(\mathrm{OR}=1.11, p<$ $0.01)$ and aggression $(\mathrm{OR}=1.04, p<0.01)$ factors were significant predictors of suicidal ideation (See Table 2).

Because of the skewed nature of the distribution in those who endorsed suicidal ideation, a second regression analysis was completed in order to determine if a unique set of variables predicted more severe suicidal ideation. In this analysis those who did not endorse any suicidal ideation $(\mathrm{n}=1,572)$ were considered one group and individuals endorsing the top $25 \%$ of suicidal ideation severity were considered the suicidal group $(\mathrm{n}=99)$. This model was significant $(X=271.923 \mathrm{df}=11, p<0.01)$. Again, none of the demographic variables, motor symptoms, or cognitive impairments were significant predictors of suicidal ideation. As with the previous analysis, results showed increased depression $(\mathrm{OR}=1.14, p<0.01)$ and aggression $(\mathrm{OR}=1.05, p<0.01)$ were significantly predictive of suicidal ideation. In addition, a past or current history of alcohol abuse was a significant predictor of suicidal ideation in this model $(\mathrm{OR}=.41, p<0.01$; see Tables 2 and 3$)$.

\section{Discussion}

Suicidal ideation (26.5 percent) and self-reported history of suicide attempts (9.5 percent) were high in the current sample of individuals with HD and consistent with the literature (Cummings, 1995; Kessler et al., 2005). The rates of suicidal ideation and history of attempted suicide in HD are significantly elevated compared with rates in the general population. For instance, Kessler and colleagues (2005) reported that 3.3 percent of individuals in the 2001-2003 National Comorbidity Survey Replication report current suicidal ideation, and less than 1 percent of participants reported a history of a suicide attempt.

Consistent with research in other populations (Chioqueta and Stiles, 2003; Turecki, 2005), suicidal ideation in HD was associated with psychiatric symptoms including depression, 
anxiety, and aggression. More severe suicidal ideation was also associated with increased rates of past and/or present alcohol abuse. In contrast to risk factors in other samples (Harris and Barraclough, 1997), there was no association between obsessive compulsive symptoms and suicidal ideation in the current study. While obsessive and compulsive symptoms are not uncommon among individuals with HD (Anderson et al., 2001; Beglinger et al., 2007), it is rare that individuals with $\mathrm{HD}$ meet criteria for a diagnosis of OCD.

While the current study showed significant relations between suicidal ideation and psychiatric symptoms among individuals with HD, the effect sizes were relatively small. This is in contrast to previous literature in both community samples and in individuals with medical illnesses, which document strong associations between psychiatric symptoms, particularly depression and suicidality. Since the relation between suicidality and psychiatric symptoms is attenuated in individuals with HD, further research is needed to better understand suicide risk in this disease. Components worthy of further study include impulsivity, which is a well-known characteristic of HD, but not assessed in this study. Given the interruption of frontal-subcortical circuitry in HD, it is possible that suicide in HD may result from the inability to inhibit emotionally-driven behavior. In addition, it will be important to consider the impact of other cognitive measures on the ideation and completion of suicide in HD. The lack of association of suicidal ideation with advancing disease could be due to cognitive decline or lack of insight.

Many individuals with HD have observed their parents and other family members experience the progression of HD. It is unknown what impact an individual's previous experience with HD may have on suicidal ideation. Another possibility may be that an interaction exists between disability (or perceived disability) and intent to harm oneself. This possibility is supported by reports that suicide increases in the stages of HD where significant functional decline is evident (i.e., loss of employment or driving; Paulsen et al., 2005). However, data in the current study did not support a linear relationship between advancing disease (i.e., increased motor symptoms and cognitive impairment) and increased rates of suicidal ideation. Finally, suicidal ideation in HD may be associated with consideration of so-called "rationale suicide" where persons with a terminal illness plan cessation of life to cease perceived suffering. Although opposed by most legal, medical, and religious communities, this issue received a great deal of attention in the past decade since Dr. Kevorkian's high-profile conviction of assisted suicides in terminal patients. The Oregon legislature since enacted the Death with Dignity Act (DWDA), which allows physicians to prescribe lethal medication to adults diagnosed with a terminal illness that will result in death within six months. Although no known survey has queried patients with degenerative disease on this debate, informal reports of dialogue among HD families has been reported.

Findings from this study are consistent with reports that suicide in HD is greater than those reported in other neurodegenerative diseases (Druss and Pincus, 2000; Harris and Barraclough, 1997). Druss and Pincus (2000) found that the presence of medical conditions were associated with increased rates of suicidal ideation and suicide attempts even after controlling for depression and alcohol use. Further, they argued that the simple presence of a medical condition likely served as a proxy for associated factors such as increased disability or chronic pain. Goodwin and Olfson (2002) observed that perception of poor health among individuals with medical conditions was associated with increased levels of suicidal ideation. It is hypothesized that increased disability and perception of poor health may be viewed as reasons for feeling life may not be worth living (Druss and Pincus, 2000; Goodwin and Olfson, 2002).

An important consideration in the current study is the fact that we assessed suicidal ideation rather than completed suicide. Much of the literature assessing the relation between 
suicidality and psychiatric diagnoses looks at the presence of psychiatric diagnoses among individuals who completed suicide. Bertolote and colleagues (2003), for example, reported that approximately $90 \%$ of individuals who complete a suicide have a diagnosable psychiatric condition at the time of death. If our participants were followed longitudinally, it is possible that some portion will attempt and/or complete suicide. The presence of psychiatric symptoms, such as depression or substance abuse, may prove useful in identifying individuals who are at a particularly high risk for attempting or completing a suicide. It is possible that different factors predict individuals with suicidal ideation and those who follow through with attempting and completing suicide.

One important limitation of the current study is the limited measures of psychiatric symptoms used in the current study, the UHDRS. It is possible that more fine grained, well validated measures of psychiatric symptoms may have improved the ability to predict the presence or absence of suicidal ideation. Similarly, it is likely that additional factors not assessed in the current study may be useful predictors of suicidal ideation among individuals with HD. Impulsivity, for example, was not measured in the current study, but it has been observed to be predictive of individuals who attempt and complete suicide in other populations (i.e., Zouk et al., 2006). This is an important area for future research in HD, as impulsivity is commonly observed in HD due to disruption of frontal-subcortical circuitry. Other potential constructs that may be useful in predicting suicidality in HD include measures of family psychiatric and suicide history, incarceration, and social support.

There are obvious clinical implications of the current findings. First, we replicate and punctuate previous reports of increased suicidality in HD. Health care professionals are strongly encouraged to assess for suicidal ideation among all individuals with HD in the form of direct questions or a self-report questionnaire. While individuals with comorbid psychiatric symptoms may be at particularly high risk for suicidal ideation, the absence of psychiatric symptoms does not indicate that there is a lack of suicidal ideation. As such, it is important that screening for suicidal ideation occurs on a regular basis among individuals with HD. If health care professionals do determine that suicidal ideation is present, steps should be taken to refer individuals to the appropriate mental health professionals and to ensure the individual's safety.

Suicidality is frequent in HD and may herald a potentially preventable cause of premature death in this disorder. Findings show that psychiatric symptoms including depression, anxiety, aggression, and alcohol abuse are associated with increased rates of suicidal ideation in Huntington disease. Further research is needed with comprehensive measures of psychiatric disorders and longitudinal study designs to further clarify the role of psychiatric comorbidity to suicidality in HD. Further study of this phenomena may lead to meaningful interventions, at a time when new clinical trials and potentially meaningful therapies are on the horizon.

\section{Acknowledgments}

This research is supported by the National Institutes for Health, National Institute of Neurological Disorders and Stroke (NS40068) and CHDI Foundation, Inc.

Participating investigators as part of the Huntington Disease Research Group at The University of Iowa included Carissa Gehl, PhD; Elizabeth Penziner, MA; Doug Langbehn, PhD; and Jane S. Paulsen, PhD. Participating investigators of the Huntington Study Group were Jane S. Paulsen, PhD and Kathleen Shannon, MD. Academic advisors who assisted in the completion of this project were Judy Schiffman, MSW; Lisa Dellefave, MS; and Kelly Ormond, MS. 


\section{References}

Almqvist EW, Brinkman RR, Wiggins S, Hayden MR. Canadian Collaborative Study of Predictive Testing, 2003. Psychological consequences and predictors of adverse events in the first 5 years after predictive testing for Huntington's disease. Clinical Genetics. 64:300-309. [PubMed: 12974735]

Anderson KE, Louis ED, Stern Y, Marder KS. Cognitive correlates of obsessive and compulsive symptoms in Huntington's disease. American Journal of Psychiatry. 2001; 158:799-801. [PubMed: 11329405]

Beglinger LJ, Langbehn DR, Duff K, Stierman L, Black DW, Nehl C, Anderson K, Penziner E, Paulsen JS. Investigators of the Huntington Study Group, 2007. Probability of obsessive and compulsive symptoms in Huntington's disease. Biological Psychiatry. 61:415-418. [PubMed: 16839521]

Beglinger LJ, Paulsen JS, Watson DB, Wang C, Duff K, Langbehn DR, Moser DJ, Paulson HL, Aylward EH, Carlozzi NE, Queller S, Stout JC. Obsessive and compulsive symptoms in prediagnosed Huntington's disease. Journal of Clinical Psychiatry. 2008; 69:1758-1765. [PubMed: 19012814]

Berrios GE, Wagle AC, Markova IS, Wagle SA, Ho LW, Rubinsztein DC, Whittaker J, FfrenchConstant C, Kershaw A, Rosser A, Bak T, Hodges JR. Psychiatric symptoms and CAG repeats in neurologically asymptomatic Huntington's disease gene carriers. Psychiatry Research. 2001; 102:217-225. [PubMed: 11440772]

Bertolote JM, Fleischmann A, De Leo D, Wasserman D. Suicide and mental disorders: Do we know enough? British Journal of Psychiatry. 2003; 183:382-383. [PubMed: 14594911]

Brezo J, Paris J, Turecki G. Personality traits as correlates of suicidal ideation, suicide attempts, and suicide completions: a systematic review. ACTA Psychiatrica Scandinavica. 2006; 113:180-206. [PubMed: 16466403]

Campodonico JR, Codori AM, Brandt J. Neuropsychological stability over two years in asymptomatic carriers of the Huntington's disease mutation. Journal of Neurology, Neurosurgery \& Psychiatry. 1996; 61:621-624.

Cheng AT. Mental illness and suicide. A case-control study in east Taiwan. Archives of General Psychiatry. 1995; 52:594-603. [PubMed: 7598636]

Chioqueta AP, Stiles TC. Suicide risk in outpatients with specific mood and anxiety disorders. Crisis. 2003; 24:105-112. [PubMed: 14518643]

Conwell Y, Duberstein PR, Cox C, Herrmann JH, Forbes NT, Caine ED. Relationships of age and axis I diagnoses in victims of completed suicide: a psychological autopsy study. American Journal of Psychiatry. 1996; 153:1001-1008. [PubMed: 8678167]

Craufurd D, Thompson JC, Snowden JS. Behavioral changes in Huntington Disease. Neuropsychiatry, Neuropsychology, and Behavioral Neurology. 2001; 14:219-226.

Cummings, J. Behavioral and psychiatric symptoms associated with Huntington disease. In: Weiner, WJ.; Lang, AE., editors. Behavioral Neurology of Movement Disorders. Raven Press; New York: 1995. p. 179-186.

Dewhurst K, Oliver JE, McKnight AL. Socio-psychiatric consequences of Huntington's disease. British Journal of Psychiatry. 1970; 116:255-258. [PubMed: 4244788]

Druss B, Pincus H. Suicidal ideation and suicide attempts in general medical illnesses. Archives of Internal Medicine. 2000; 160:1522-1526. [PubMed: 10826468]

Duff K, Paulsen JS, Beglinger LJ, Langbehn DR, Stout JC. Psychiatric symptoms in Huntington's disease before diagnosis: the Predict-HD study. Biological Psychiatry. 2007; 62:1341-1346. [PubMed: 17481592]

Farrer LA. Suicide and attempted suicide in Huntington disease: implications for preclinical testing of persons at risk. American Journal of Medical Genetics. 1986; 24:305-311. [PubMed: 2940862]

Ferrante RJ, Gutekunst CA, Persichetti F, McNeil SM, Kowall NW, Gusella JF, MacDonald ME, Beal MF, Hersch SM. Heterogeneous topographic and cellular distribution of huntingtin expression in the normal human neostriatum. Journal of Neuroscience. 1997; 17:3052-3063. [PubMed: 9096140] 
Folstein S, Abbott MH, Chase GA, Jensen BA, Folstein MF. The association of affective disorder with Huntington's disease in a case series and in families. Psychological Medicine. 1983; 13:537-542. [PubMed: 6226055]

Goodwin R, Olfson M. Self-perception of poor health and suicidal ideation in medical patients. Psychological Medicine. 2002; 32:1293-1299. [PubMed: 12420898]

Harper PS. The epidemiology of Huntington's disease. Human Genetics. 1992; 89:365-376. [PubMed: 1535611]

Harris EC, Barraclough B. Suicide as an outcome for mental disorders. A meta-analysis. British Journal of Psychiatry. 1997; 170:205-228. [PubMed: 9229027]

Huntington Study Group. Unified Huntington's Disease Rating Scale: reliability and consistency. Movement Disorders. 1996; 11:136-142. [PubMed: 8684382]

Kessler RC, Berglund P, Borges G, Nock M, Wang PS. Trends in suicide ideation, plans, gestures, and attempts in the United States, 1990-1992 to 2001-2003. JAMA. 2005; 293:2487-2495. [PubMed: 15914749]

Kessler RC, Borges G, Walters EE. Prevalence of and risk factors for lifetime suicide attempts in the National Comorbidity Survey. Archives of General Psychiatry. 1999; 56:617-626. [PubMed: 10401507]

Marder K, Zhao H, Myers RH, Cudkowicz M, Kayson E, Kieburtz K, Orme C, Paulsen J, Penney JB Jr. Siemers E, Shoulson I, Huntington Study Group. Rate of functional decline in Huntington's disease. Neurology. 2000; 54:452-458. [PubMed: 10668713]

Mayeux R, Stern Y, Herman A, Greenbaum L, Fahn S. Correlates of early disability in Huntington's disease. Annals of Neurology. 1986; 20:727-731. [PubMed: 2949692]

Paulsen JS, Hoth KF, Nehl C, Stierman L. Critical periods of suicide risk in Huntington's disease. American Journal of Psychiatry. 2005; 162:725-731. [PubMed: 15800145]

Paulsen JS, Ready RE, Hamilton JM, Mega MS, Cummings JL. Neuropsychiatric aspects of Huntington's disease. Journal of Neurology, Neurosurgery \& Psychiatry. 2001; 71:310-314.

Paulsen, JS.; Robinson, RG. Huntington disease. In: Hodges, JR., editor. Early-onset dementia: a multidisciplinary approach. Oxford University Press; New York: 2001. p. 338-366.

Preuss UW, Schuckit MA, Smith TL, Danko GP, Buckman K, Bierut L, Bucholz KK, Hesselbrock MN, Hesselbrock VM, Reich T. Comparison of 3190 alcohol-dependent individuals with and without suicide attempts. Alcoholism, Clinical and Experimental Research. 2002; 26:471-477.

Robins Wahlin TB, Backman L, Lundin A, Haegermark A, Winblad B, Anvret M. High suicidal ideation in persons testing for Huntington's disease. ACTA Neurologica Scandinavica. 2000; 102:150-161. [PubMed: 10987374]

Sher L. Alcoholism and suicidal behavior: a clinical overview. ACTA Psychiatrica Scandinavica. 2006; 113:13-22. [PubMed: 16390364]

Spalletta G, Troisi A, Saracco M, Ciani N, Pasini A. Symptom profile, Axis II comorbidity and suicidal behaviour in young males with DSM-III-R depressive illnesses. Journal of Affective Disorders. 1996; 39:141-148. [PubMed: 8827424]

Turecki G. Dissecting the suicide phenotype: the role of impulsive-aggressive behaviours. Journal of Psychiatry and Neuroscience. 2005; 30:398-408. [PubMed: 16327873]

van Duijn E, Kingma EM, Timman R, Zitman FG, Tibben A, Roos RA, van der Mast RC. Crosssectional study on prevalences of psychiatric disorders in mutation carriers of Huntington's disease compared with mutation-negative first-degree relatives. Journal of Clinical Psychiatry. 2008; 69:1804-1810. [PubMed: 19026253]

Yen S, Shea MT, Pagano M, Sanislow CA, Grilo CM, McGlashan TH, Skodol AE, Bender DS, Zanarini MC, Gunderson JG, Morey LC. Axis I and axis II disorders as predictors of prospective suicide attempts: findings from the collaborative longitudinal personality disorders study. Journal of Abnormal Psychology. 2003; 112:375-381. [PubMed: 12943016]

Zouk H, Tousignant M, Seguin M, Lesage A, Turecki G. Characterization of impulsivity in suicide completers: clinical, behavioral and psychosocial dimensions. Journal of Affective Disorders. 2006; 92:195-204. [PubMed: 16545465] 


\section{Table 1}

Demographic Information

\begin{tabular}{ll}
\hline & $\begin{array}{c}\text { Mean (SD) } \\
\mathbf{N = 1 , 9 4 1}\end{array}$ \\
\hline Age & $47.29(12.35)$ \\
Education (years) & $13.11(2.91)$ \\
Duration of HD (years) & $6.65(4.98)$ \\
Sex (\% female) & $51.1 \%$ \\
\hline
\end{tabular}

Psychiatry Res. Author manuscript; available in PMC 2013 October 04. 
Table 2

Logistic Regression for Suicidal Ideation

\begin{tabular}{llll}
\hline & OR & $\mathbf{9 5 \%} \mathbf{C I}$ & $\boldsymbol{p}$-value \\
\hline Sex & 1.35 & $1.03-1.77$ & 0.03 \\
Education & 0.99 & $0.95-1.04$ & 0.79 \\
Age & 0.99 & $0.98-1.00$ & 0.13 \\
SDMT & 1.00 & $1.00-1.01$ & 0.54 \\
Depression/Anxiety & $\mathbf{1 . 1 1}$ & $\mathbf{1 . 1 0 - 1 . 1 3}$ & $<\mathbf{0 . 0 0 1}$ \\
Aggression & $\mathbf{1 . 0 4}$ & $\mathbf{1 . 0 2}-\mathbf{1 . 0 6}$ & $<\mathbf{0 . 0 0 1}$ \\
Obsession/Compulsion & 0.99 & $0.96-1.01$ & 0.26 \\
Motor Total & 1.01 & $1.00-1.025$ & 0.22 \\
Alcohol Abuse & 0.69 & $0.49-0.96$ & 0.03 \\
Tobacco Abuse & 0.90 & $0.68-1.18$ & 0.44 \\
Drug Abuse & 0.99 & $0.65-1.50$ & 0.96 \\
\hline
\end{tabular}

Psychiatry Res. Author manuscript; available in PMC 2013 October 04. 


\section{Table 3}

Logistic Regression for Suicidal Ideation for those with Highest Suicidal Ideation Ratings

\begin{tabular}{llll}
\hline & OR & $\mathbf{9 5 \%} \mathbf{C I}$ & $\boldsymbol{p}$-value \\
\hline Sex & 1.03 & $0.61-1.74$ & 0.91 \\
Education & 1.02 & $0.93-1.11$ & 0.73 \\
Age & 0.99 & $0.96-1.01$ & 0.19 \\
SDMT & 1.00 & $0.98-1.01$ & 0.78 \\
Depression/Anxiety & $\mathbf{1 . 1 4}$ & $\mathbf{1 . 1 2 - 1 . 1 7}$ & $<\mathbf{0 . 0 0 1}$ \\
Aggression & $\mathbf{1 . 0 5}$ & $\mathbf{1 . 0 1 - 1 . 0 8}$ & $<\mathbf{0 . 0 0 1}$ \\
Obsession/Compulsion & 1.01 & $0.97-1.05$ & 0.58 \\
Motor Total & 1.01 & $0.99-1.02$ & 0.50 \\
Alcohol Abuse & $\mathbf{0 . 4 1}$ & $\mathbf{0 . 2 2 - 0 . 7 5}$ & $\mathbf{0 . 0 0 4}$ \\
Tobacco Abuse & 0.66 & $0.38-1.15$ & 0.14 \\
Drug Abuse & 2.08 & $0.92-4.70$ & 0.08 \\
\hline
\end{tabular}

Psychiatry Res. Author manuscript; available in PMC 2013 October 04. 